\title{
Nonobstrüktif azoospermili erkeklerde mikrodiseksiyon testiküler sperm ekstraksiyonu bașarısını etkileyen faktörler
}

\author{
Factors affecting the success of microdissection testicular sperm extraction \\ in men with non-obstructive azoospermia
}

\author{
Mazhar Ortaç®, Nusret Can Çilesiz@, Ates Kadıŏlu®
}

\section{öz}

AMAÇ: Non-obstrüktif azoospermili (NOA) erkeklerde mikrodiseksiyon testiküler sperm ekstraksiyonu (mTESE) başarısını etkileyen faktörleri araştırmak

GEREC ve YöNTEM: NOA nedeniyle mTESE yapilan toplam 379 hastaya dahil edildi. Tüm hastaların fizik muayene, hormon değerleri, testis hacimleri ve tıbbi hikayeleri kayıt altına alındı.

BULGULAR: Ortalama mTESE başarısı \%46,7 olarak saptandı. Bu oran testis patolojisi Sertoli Cell Only (SCO) olan hastalarda \%33,3, erken maturasyon arresti (MA) olan hastalarda \%43,6, geç maturasyon arresti (MA) olanlarda \%78,1, hipospermatagonez (HS) olanlarda $\% 93,75$ 'inde ve normal spermtogenez (NS) olanlarda \%100 olarak saptandı $(\mathrm{p}<0,001)$. TESE ile sperm saptanan hastalarda FSH değerlerinin anlamlı olarak daha düşük olduğu $(19,7 \pm 12,8 \mathrm{~mL} / \mathrm{U}$ vs $25,3 \pm 15,5$ $\mathrm{mL} / \mathrm{U} \mathrm{p}: 0,001)$, testis hacimlerinin ise daha büyük olduğu saptandı (p: 0,004).

SONUCุ: Testis hacmi, FSH seviyesi ve testisküler histopatoloji TESE başarısını etkileyen faktörler olarak saptandı. Bu sonuçların iyi dizayn edilmiş, geniş hasta serili çalışmalarla desteklenmesi gerekmektedir.

Anahtar Kelimeler: Azoospermi, erkek infertilitesi, testiküler sperm ekstraksiyonu

\section{ABSTRACT}

OBJECTIVE: To determine the sperm retrieval rates (SRRs) and predictive factors of patients with non-obstructive azoospermia (NOA) after testicular sperm extraction (TESE)

MATRERIAL and METHODS: A total of 311 patients who were diagnosed with non-obstructive azoospermia (NOA) and underwent TESE were included in this study. Physical examination, hormone values, testicular volumes, and the medical history of all patients were recorded RESULTS: The mean sperm retrieval rates (SRRs) were $46.7 \%$. These SRRs were $34.2 \%, 33.3 \%, 71.4 \%, 100 \%$, and $100 \%$ for Sertoli Cell Only, late maturation arrest, early maturation arrest, hypospermatogenesis, and normal spermatogenesis, respectively $(\mathrm{p}<0.001)$. While the mean FSH values were significantly lower in patients with positive mTESE $(19.7 \pm 12.8 \mathrm{~mL} / \mathrm{U}$ vs. $25.3 \pm 15.5 \mathrm{~mL} / \mathrm{U}$, p: 0.001$)$, the mean testicular volumes were larger in patients with positive TESE compared to patients with negative mTESE (p: 0.004).

CONCLUSION: The testicular histopathology, level of FSH and testicular volume were identified as independent predictors of SRRs for men with NOA

Keywords: Azoospermia, male infertilite, testicular sperm extraction

sperm elde yöntemi olarak konvansiyonel testiküler sperm ekstraksiyonu (TESE) uygulanırken, Schlegel P. ve ark. 1999 yilında ilk defa mikroskop kullanarak bu tekniği geliştirip mikro-disseksiyon TESE (mTESE) olarak tarif etmişlerdir. ${ }^{[2]}$ Günümüzde mTESE NOA'l hastalarda sperm elde etmek için altın standart teknik olarak kabul edilmektedir. Mevcut literatüre bakıldığında NOA'lı hastalarda mTESE ile sperm bulma şansı yaklaşık $\% 56^{\prime} \mathrm{d} ı r .^{[3-5]}$

Mikro TESE’nin tarif edilmesinden beri bu işlemin başarısı için pek çok prediktif faktör çalışılmıştır. Bunlardan en sık çalışılanlar; folikül uyarıcı hormon (FSH), testosteron ve inhibin-B düzeyleri, testis hacmi ve testiküler histopatolojik bulgular, inmemiş testis öyküsü, Klinefelter sendromu ve AZF gen delesyonları gibi genetik hastalıklardır. ${ }^{[4,6,7]}$ Bununla birlikte, mevcut literatüre göre, sadece testis 
histopatolojik bulguları mTESE'de sperm elde etme oranı ile güçlü bir şekilde ilişkilidir. ${ }^{[7-10]} \mathrm{Bu}$ çalışmanın amacı, NOA tanılı hastalarda sperm elde etme oranlarını etkiliyen prediktif faktörlerin değerlendirilmesidir.

\section{GEREÇ VE YÖNTEM}

$\mathrm{Bu}$ retrospektif çalışmaya, mTESE uygulanan NOA tanı$1_{1}$ hastalardan oluşan tek bir merkezden toplam 379 hasta dahil edildi. Tüm hastalarda NOA tanısı tıbbi öykü, fizik muayene, ardışık iki semen analizi ve FSH, testosteron düzeyi ile doğrulandı. Semen örnekleri androloji laboratuvarında görsel ve visual stimülasyon ile mastürbasyon yoluyla elde edildi. Tüm semen örnekleri, androloji laboratuvarında, Dünya Sağlık Örgütü (WHO) laboratuvar el kitabının, insan semeninin 1999 (2010'dan önce) ve 2010 (2010'dan sonra) incelemesi ve işlenmesi kriterine göre analiz edildi. [11] Yaş, tıbbi ve aile öyküleri, testis hacmi, komorbiditeleri, klinik muayene bulguları gibi kısa demografik detaylar kaydedildi. Her iki testis hacminin ortalama değerleri bir Prader orkidometre (ASSI, Westbury, NY, ABD) aracılığıyla kaydedildi. Tüm hastalar karyotip analizi ve Y-kromozomal mikrodelesyonu ile tarand.

Tüm hastalara daha önce tarif edilen mTESE prosedürü uygulanıp $^{[1]}$, mTESE işlemi sırasında histopatolojik tanı için doku örneği alındı. Retrospektif hasta taraması için kurumsal çalışma onayı alındı.

\section{istatistik}

İstatistik analizde SPSS for Windows 20,0 (SPSS Inc, Chicago, IL) paketi kullanıldı. Kolmogorov-Smirnov normalite testine göre parametreler incelendi. Normal dağılıma uyan nicel değerler için parametrik testler (student' t test), uymayanlarda non parametrik testler (MannWhitney U) kullanıldı. Kalitatif veriler için ki-kare testi uygulandi. Univariate lojistik regresyon analizi ile TESE başarısı üzerindeki etkisi incelendi. P değerinin 0,05 'den küçük olması istatistiksel olarak anlamlı kabul edildi.

\section{BULGULAR}

Toplam 379 hastanın demografik özellikleri ve klinik özellikleri Tablo 1'de gösterilmiştir. Tüm hastaların ortalama yaşları 34,1 $\pm 5,8$ iken, Toplam $177(\% 46,7)$ hastada mTESE işlemi ile sperm bulundu.

Hastalar sperm bulunma durumuna göre ayrıldığında, testisküler patoloji ile sperm bulma oranı arasında güçlü bir korelasyon olduğu görülmektedir. Testiküler histopatoloji; Sertoli Cell Only (SCO) olarak rapor edilen hastaların \%33,3'ünde sperm saptanırken, erken maturasyon arresti (MA) olanların \%43,6, geç maturasyon arresti (MA) olanların \%78,1'inde, hipospermatagonezis (HS) olanların \%93,75'inde, normal spermatogenezis (NS) olanların tümünde sperm saptanmıştır ( $\mathrm{p}<0,001)$ (Tablo 2).

Sperm bulunma oranlarını etkileyen diğer parametreler bakıldığında testis hacmi ve FSH seviyesinin anlamlı olarak sperm bulma oranı ile ilişkili olduğu saptanmıştır. Fakat ortalama testosteron düzeylerinin sperm bulma oranları üzerinde etkisi yoktu $(3,7 \pm 1,7$ vs 4,6 $\pm 9,3 \mathrm{ng} / \mathrm{dL}$ p: 0,822). Yapılan Tek değişkenli analizde sperm saptanan hastalarda FSH değeri 19,7 $\pm 12,8$ IU/L olarak saptanırken, sperm bulunamayan hastalarda ortalama FSH değerinin 25,3 $\pm 15,5$ IU/L olduğu görülmektedir (p: 0,001). Her iki grubu testis

Tablo 1. Hastaların demografik verileri

\begin{tabular}{lc} 
Hasta Sayısı (n) & 379 \\
Yaş/yıl* & $34,1 \pm 5,8$ \\
Sağ Testis Hacmi/mL* & $12,0 \pm 5,4$ \\
Sol Testis Hacmi/mL* & $11,5 \pm 5,1$ \\
FSH IU/L* & $22,8 \pm 14,6$ \\
Testosteron ng/dL* & $4,1 \pm 6,4$ \\
Sperm (+) & $177(46,7 \%)$ \\
\hline$*$ Mean \pm SD & \\
$* P<0,05$ is defined as statistical significance. & \\
Sperm (+): TESE ile sperm elde edilen hastalar & \\
FSH: follicle-stimulating hormone & \\
Normal aralık: FSH $\left(1,5-12,4\right.$ IU I $\left.{ }^{-1}\right)$; testosterone: $\left(2,18-9,06 \mathrm{ng} \mathrm{dL}^{-1}\right)$
\end{tabular}

Tablo 2. Testiküler histopatolojiye ve sperm elde etme oranları arasındaki ilişki

\begin{tabular}{|c|c|c|c|c|}
\hline Testis Patolojisi & $\begin{array}{c}\text { Hasta sayısı: } 379 \\
\text { N (\%) }\end{array}$ & $\begin{array}{c}\text { Sperm (-) } \\
N(\%)\end{array}$ & $\begin{array}{c}\text { Sperm (+) } \\
N(\%)\end{array}$ & $p$ \\
\hline Sertoli Cell Only & $243(64,11)$ & $162(80,2)$ & $81(45,8)$ & $0,001^{*}$ \\
\hline Geç maturasyon arresti & $55(14,51)$ & $31(15,3)$ & $24(13,6)$ & 0,622 \\
\hline Erken maturasyon arresti & $32(8,44)$ & $7(3,5)$ & $25(14,1)$ & $0,001^{*}$ \\
\hline Hipospermatogenesis & $32(8,44)$ & $2(1,0)$ & $30(16,9)$ & $0,001^{*}$ \\
\hline Normal spermatogenesis & $17(4,48)$ & 0 & $17(9,6)$ & $0,001^{*}$ \\
\hline
\end{tabular}

$\mathrm{P}<0,05$ is defined as statistical significance.

Sperm (+): TESE ile sperm elde edilen hastalar

Sperm (-): TESE ile sperm elde edilemeyen hastalar 
Tablo 3. TESE ile sperm bulunan ve bulunmayan hastaların karşılaştırılması

\begin{tabular}{lccc}
\hline & Sperm (-) & Sperm (+) & $p$ \\
\hline Hasta Sayısı (n) & 202 & 177 & 0,658 \\
Yaş (yıl)* & $34,3 \pm 5,6$ & $33,9 \pm 5,6$ & $0,004^{*}$ \\
Sağ Testis Hacmi/mL* & $11,1 \pm 5,1$ & $12,9 \pm 5,5$ & $0,001^{*}$ \\
Sol Testis Hacmi/mL* & $10,6 \pm 5,1$ & $12,5 \pm 4,9$ & $0,001^{*}$ \\
FSH IU/L* & $25,3 \pm 15,5$ & $19,7 \pm 12,8$ & 0,822 \\
Testosteron ng/dL* & $3,7 \pm 1,7$ & $4,6 \pm 9,3$ & \\
\hline
\end{tabular}

$*$ Mean \pm SD

* $P<0,05$ is defined as statistical significance.

Sperm (+): TESE ile sperm elde edilen hastalar

Sperm (-): TESE ile sperm bulunamayan hastalar

FSH: follicle-stimulating hormone

Normal aralık: FSH (1,5-12,4 IU I-1 ); testosterone: $\left(2,18-9,06 \mathrm{ng} \mathrm{dL}^{-1}\right)$

hacimlerine göre kıyasladığımızda ise sperm saptanan hastalarda ortalama sağ testis hacmi $12,9 \pm 5,5 \mathrm{~mL}$, sol testis hacmi ise $12,5 \pm 4,9 \mathrm{~mL}$ olduğu saptanırken, sperm bulunmayan hastalarda bu testis hacimleri sırasıyla $10,6 \pm 5,1$, $11,1 \pm 5,1 \mathrm{~mL}$ olarak saptanmıştır. Her iki testis hacimleri arasındaki farkın istatistiksel olarak anlamlı olduğu görülmüştür. (Sağ testis, p: 0,001, Sol testis, p: 0,004). (Tablo 3)

\section{TARTIȘMA}

NOA, genetik anormallikler, inmemiş testisler, orşit, travma ve endokrin bozukluklar gibi çeşitli nedenlerden kaynaklanan bir testiküler fonksiyon bozukluğudur. Son zamanlarda yapilan birçok çalışma sonucuna göre, mTESE etiyolojiden bağımsız olarak NOA hastalarında sperm elde etmek için altın standart teknik olarak kabul edilmektedir. [1,12] Mevcut literatüre göre, mTESE ile bildirilen sperm elde oranları \%42,9 ile 63 arasında değişmektedir. ${ }^{[3-5,13]}$

Bu çalışmada NOA hastalarda mTESE ile sperm bulma oranı $\% 46,7$ olarak saptanmıştır. Sonuçlar itibari ile önceki literatür ile uyumlu olduğu görülmektedir. Sperm bulma oranının testiküler patolojiye göre sınıflandırdığımızda; SCO grubunda \%33,3, erken MA grubunda \%43,6, geç MA grubunda \%78,1, HS grubunda $\% 93,7$ ve NS grubunda \%100 idi. Benzer bir çalışma Schlegel ve ark. tarafından yapılmış olup ortalama sperm bulma oranlarının; HS grubunda \%73-100 ile en yüksek orana sahip iken, geç MA grubunda \%27-86, erken MA grubunda \%2740 ve testis histolojisinin sperm bulma açısından en kötü prognoza sahip olduğu SCO'lu hastalarda \%22,5-41 oranı ile sperm elde edilmiştir. ${ }^{[12]}$ Abdel Raheem ve ark. yaptığı toplam 388 hastayı içeren seride mTESE başarısının \%50 olduğu bildirilmiştir. Benzer şekilde çalışmanın sonuçlarının testis histolojisi ile güçlü bir şekilde ilişkili olduğu belirtilmiştir. Bu çalışmada mTESE başarısı; SCO grubunda $\% 24$, MA grubunda $\% 37$, HS grubunda $\% 94$ ve NS grubunda $\% 100$ olduğunu göstermişlerdir. ${ }^{[0]}$
Testis hacminin mTESE başarısına etkisi net olarak bilinmemektedir. Mevcut literatürde bir testis hacminin sperm bulma oranlarına etkisi olmadığı hatta $2 \mathrm{ml}$ altında ki testis hacimlerinde bile benzer başarının sağlanabileceği gösterilmiştir. ${ }^{[14]}$ Buna rağmen birçok çalışmada testis hacmi büyük olan hastalarda mTESE başarısının daha yüksek olduğu rapor edilmiştir. ${ }^{[15,16]}$

$\mathrm{Bu}$ çalışmada ise sperm bulma oranlarının testis hacmi ile ilişkili olduğu saptanmıştır. Bryson CF ve ark. yaptığı toplam 1127 hastayı değerlendirdiği çalışmada, hastalar testis hacmi $<2 \mathrm{~mL}, 2-5 \mathrm{~mL}$ ve $>5 \mathrm{ml}$ olmak üzere 3 gruba ayrılmıştır. Bu üç gruptaki sperm bulma oranlarının sırasıyla $\% 55, \% 56$ ve $\% 55$ olduğu, bu oranların arasında istatistiksel bir fark olmadığını göstermişlerdir. ${ }^{[14]}$ Marconi ve ark. ise 8 mL'den düşük testis hacimleri ve FSH düzeylerinin >12,4IU olan hastalarda, mikro-TESE başarısının yaklaşık \%30 olarak azaldığını göstermişlerdir. ${ }^{[15]}$ Başka bir çalışmada Bromage ve ark.'nın 106 hastayı dahil ettiği çalışmada, testis hacmi $<4 \mathrm{~mL}$ veya FSH seviyeleri $>10$ olan hastalarda TESE sperm bulma oranın istatistiksel anlamlı olarak azaldığını (\%29) bildirmiştir. Benzer şekilde, Ziaee ve ark. tarafından NOA'l 85 hastanın değerlendirildiği başka bir çalışmada, TESE ile sperm elde edilen hastalarda ortalama testis hacmi 17,5 mL iken sperm saptanmayan hastalarda ise ortalama testis hacminin $5,7 \mathrm{~mL}$ olduğu bildirilmiştir. ${ }^{[17]}$

FSH spermatogenezin regülasyonunda önemli rol almaktadır. Fakat spermatogenez için gerekli FSH seviyesi net olarak gösterilmemiştir. ${ }^{[18]} \mathrm{NOA}$ olan hastalarda FSH seviyesinin mTESE başarısı üzerindeki etkisi birçok çalışmada araştırılmıştır. ${ }^{[4]} \mathrm{Bu}$ çalışmada sperm elde edilen hastalarda FSH seviyesinin sperm bulunmayan gruba göre anlamlı olarak daha düşük olduğu saptandı $(19,7 \pm 12,8$ IU/L vs. $25,3 \pm 15,5$ IU/L p: 0,001). Ramasamy ve ark. 792 hastayı dahil ettiği çalışmada FSH $<15 \mathrm{~mL} / \mathrm{U}$ olan hastalarda sperm elde oranlarının daha düşük olduğunu 
göstermişlerdir. ${ }^{[6]}$ Başka bir çalışmada ise $\mathrm{FSH}<17$ olması sperm elde başarısı için prediktif bir faktör olduğu gösterilmiştir. ${ }^{[19]}$

Sonuç olarak NOA hastalarda mTESE ile neredeyse hastaların yarısında sperm elde edilebilmektedir. Testis hacmi, FSH seviyesi ve testisküler histopatoloji TESE başarısını etkileyen faktörler olarak görülmektedir. Bu sonuçların iyi dizayn edilmiş, geniş hasta serili çalışmalarla desteklenmesi gerekmektedir.

\section{Hakem Değerlendirmesi}

Dış bağımsız

Çıkar Çatışması

Yazarlar çıkar ilişkisi olmadığını beyan etmişlerdir.

\section{Finansal Destek}

Herhangi bir mali destek alınmamıștır.

\section{Peer-review}

Externally peer-reviewed.

\section{Conflict of Interest}

No conflict of interest was declared by the authors.

Financial Disclosure

No financial disclosure was received.

\section{KAYNAKLAR}

1. Schlegel PN, Li PS. Microdissection TESE. sperm retrieval in non-obstructive azoospermia. Hum Reprod Update 1998;4:439. [CrossRef]

2. Schlegel PN. Testicular sperm extraction: microdissection improves sperm yield with minimal tissue excision. Hum Reprod 1999;14:131-5. [CrossRef]

3. Bernie AM, Mata DA, Ramasamy R, Schlegel PN. Comparison of microdissection testicular sperm extraction, conventional testicular sperm extraction, and testicular sperm aspiration for nonobstructive azoospermia: a systematic review and meta-analysis. Fertil Steril 2015;104:1099-103.e3. [CrossRef]

4. Bernie AM, Ramasamy R, Schlegel PN. Predictive factors of successful microdissection testicular sperm extraction. Basic Clin Androl 2013;23:5. [CrossRef]

5. Ishikawa T. Surgical recovery of sperm in non-obstructive azoospermia. Asian J Androl 2012;14:109-15. [CrossRef]

6. Ramasamy R, Lin K, Gosden LV, Rosenwaks Z, Palermo GD, Schlegel PN. High serum FSH levels in men with nonobstructive azoospermia does not affect success of microdissection testicular sperm extraction. Fertil Steril 2009;92:590-3. [CrossRef]
7. Caroppo E, Colpi EM, Gazzano G, Vaccalluzzo L, Scroppo FI, D’Amato G, Colpi GM. Testicular histology may predict the successful sperm retrieval in patients with non-obstructive azoospermia undergoing conventional TESE. a diagnostic accuracy study. J Assist Reprod Genet 2017;34:149-54. [CrossRef]

8. Tash JA, Schlegel PN. Histologic effects of testicular sperm extraction on the testicle in men with nonobstructive azoospermia. Urology 2001;57:334-7. [CrossRef]

9. Bernie AM, Shah K, Halpern JA, Scovell J, Ramasamy R, Robinson B, Schlegel PN. Outcomes of microdissection testicular sperm extraction in men with nonobstructive azoospermia due to maturation arrest. Fertil Steril 2015;104:569-73. [CrossRef]

10. Abdel Raheem A, Garaffa G, Rushwan N, De Luca F, Zacharakis E, Abdel Raheem T, et al. Testicular histopathology as a predictor of a positive sperm retrieval in men with non-obstructive azoospermia. BJU Int 2013;111:492-9. [CrossRef]

11. Organization WHO. WHO laboratory manual for the examination and processing of human semen, 5th ed. Geneva: World Health Organization, Department of Reproductive Health and Research; 2010.

12. Flannigan R, Bach PV, Schlegel PN. Microdissection testicular sperm extraction. Transl Androl Urol 2017;6:745-52. [CrossRef]

13. Donoso P, Tournaye H, Devroey P. Which is the best sperm retrieval technique for non-obstructive azoospermia? A systematic review. Hum Reprod Update 2007;13:539-49. [CrossRef]

14. Bryson CF, Ramasamy R, Sheehan M, Palermo GD, Rosenwaks Z, Schlegel PN. Severe testicular atrophy does not affect the success of microdissection testicular sperm extraction. J Urol 2014;191:1758. [CrossRef]

15. Marconi M, Keudel A, Diemer T, Bergmann M, Steger K, Schuppe HC, Weidner W. Combined trifocal and microsurgical testicular sperm extraction is the best technique for testicular sperm retrieval in "low-chance" nonobstructive azoospermia. Eur Urol 2012;62:713-9. [CrossRef]

16. Bromage SJ, Falconer DA, Lieberman BA, Sangar V, Payne SR. Sperm retrieval rates in subgroups of primary azoospermic males. Eur Urol 2007;51:534-9. [CrossRef]

17. Ziaee SA, Ezzatnegad M, Nowroozi M, Jamshidian H, Abdi H, Hosseini Moghaddam SM. Prediction of successful sperm retrieval in patients with nonobstructive azoospermia. Urol J 2006;3:92-6. http://journals.sbmu.ac.ir/urolj/index.php/uj/article/view/202/200

18. Sofikitis N, Giotitsas N, Tsounapi P, Baltogiannis D, Giannakis $\mathrm{D}$, Pardalidis N. Hormonal regulation of spermatogenesis and spermiogenesis. J Steroid Biochem Mol Biol 2008;109:323-30. [CrossRef]

19. Souza CA, Cunha Filho JS, Santos D, Gratao A, Freitas FM, Passos EP. Predictive factors for motile sperm recovery using testicular biopsy in nonobstructive azoospermic patients. Int Urol Nephrol 2003;35:53-7. [CrossRef] 